\title{
Chlorogenic acid reduces inflammation in murine model of acute pancreatitis
}

\author{
Aleksandra Tarasiuk ${ }^{1} \cdot$ Kamila Bulak $^{2} \cdot$ Marcin Talar $^{1} \cdot$ Jakub Fichna $^{1}$ (D)
}

Received: 6 May 2021 / Revised: 28 July 2021 / Accepted: 30 July 2021 / Published online: 12 August 2021

(C) The Author(s) 2021

\begin{abstract}
Background The pathogenesis of acute pancreatitis (AP) initiation and progression is still unknown, and effective treatment is limited to supportive care. Many phytochemicals have the potential to alleviate AP symptoms and may be a useful and effective supplement to standard AP treatment. The objective of the study was to examine the potential role of chlorogenic acid (CGA), a polyphenol known for anti-inflammatory effect, in the treatment of experimental AP in mice.

Methods Two intraperitoneal (ip) injections of L-arginine (dosage $400 \mathrm{mg} / 100 \mathrm{~g} \mathrm{BW}$ ) were given $1 \mathrm{~h}$ apart to generate the AP murine model. Mice were separated into two experimental groups after $12 \mathrm{~h}$ from the first L-arginine injection: AP mice treated with CGA (oral gavage ( $p o$ ) every $12 \mathrm{~h} ; 20 \mathrm{mg} / \mathrm{kg} \mathrm{BW}$ ) and non-treated AP mice (po vehicle, 5\% dimethyl sulfoxide every $12 \mathrm{~h}$ ). Every $12 \mathrm{~h}$, control mice were given an equivalent volume of vehicle. At $72 \mathrm{~h}$, mice were slaughtered. Histology, as well as myeloperoxidase (MPO) and amylase activity assays, were performed on pancreatic tissues.

Results In murine mouse model of AP po administration of CGA decreased MPO vs. AP $(40.40 \pm 2.10 \mathrm{U}$ vs. $7.39 \pm 0.34$; $p<0.001)$ as well as amylase activity vs. AP $(1444 \pm 56 \mathrm{mU} / \mathrm{mL}$ vs. $3340 \pm 144 \mathrm{mU} / \mathrm{mL}$, Fig. $2 \mathrm{~B} ; p<0.001)$. When comparing CGA mice to AP mice, histological research demonstrated that the severity of AP was reduced following CGA treatment. Conclusions The current study found that CGA might have anti-inflammatory effect on L-arginine-induced pancreatitis. Dietary intervention with CGA may be advised as a supportive treatment for AP, according to our findings.
\end{abstract}

\section{Graphic abstract}
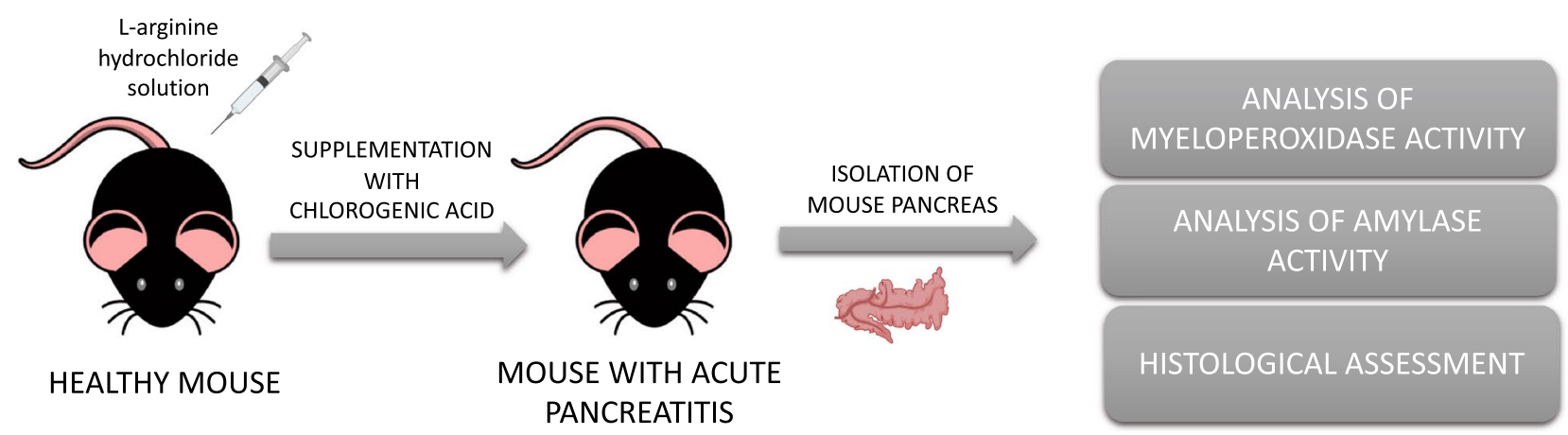

Keywords Acute pancreatitis $\cdot \mathrm{L}$-arginine induced acute pancreatitis murine model $\cdot$ Chlorogenic acid $\cdot$ Immunohistochemistry $\cdot$ Myeloperoxidase activity $\cdot$ Inflammation

\section{Abbreviations}

anti-coll-1 Anti-collagen 1

AP Acute pancreatitis

Jakub Fichna

jakub.fichna@umed.lodz.pl

Extended author information available on the last page of the article

$\begin{array}{ll}\text { BW } & \text { Body weight } \\ \text { CGA } & \text { Chlorogenic acid } \\ \text { COX-2 } & \text { Cyclooxygenase-2 } \\ \text { DMSO } & \text { Dimethyl sulfoxide } \\ \text { ECM } & \text { Extracellular matrix } \\ \text { HTAB } & \text { Hexadecyltrimethylammonium bromide }\end{array}$




$\begin{array}{ll}\text { IL } & \text { Interleukin } \\ \text { iNOS } & \text { Inducible nitric oxide synthase } \\ \text { ip } & \text { Intraperitoneal } \\ \text { MPO } & \text { Myeloperoxidase } \\ \text { MMPs } & \text { Matrix metalloproteinases } \\ \text { MMP-1 } & \text { Matrix metalloproteinase 1 (collagenase) } \\ \text { NF- } \mathrm{B} \text { - } & \text { Nuclear factor kappa-light-chain-enhancer of } \\ & \text { activated B cells } \\ \text { OD } & \text { Optical density } \\ p o & \text { Oral gavage } \\ \text { ROS } & \text { Reactive oxygen species } \\ \text { SIRS } & \text { Systemic inflammatory response syndrome } \\ \text { TNF- } \alpha & \text { Tumor necrosis factor } \alpha \\ \text { U } & \text { Units }\end{array}$

\section{Introduction}

Acute pancreatitis (AP) is a disorder of the mechanisms that inhibit or stabilize the activity of enzymes in the follicular cells of the exocrine pancreas, which in turn causes the activation of proteolytic and lipolytic pancreatic enzymes. The result can be complete destruction of the pancreas, or internal hemorrhage, caused by the digestion of the walls of the blood vessels and the gastrointestinal tract by active enzymes. In most patients, the disease is mild. However, in about $20-30 \%$ cases there are fatal consequences. The patient's death occurs very early, even a week after the onset of the first symptoms, due to a multi-organ failure. Death may also occur from sepsis around the third week of the disease; sepsis leads to an inflammatory reaction and thus an infection that may result in organ failure or dysfunction [1-5].

The diagnosis of AP is most often established by the presence of two of the three following criteria: (i) abdominal pain consistent with the disease, (ii) laboratory tests (serum amylase and/or lipase activity greater than two/three times the upper limit of normal), and/or (iii) characteristic findings from abdominal imaging [6].

Treatment of milder AP is relatively simple and involves short-term fasting (3-4 days) accompanied by intravenous rehydration and administration of painkillers. All other cases of AP are treated in the hospital, where patients are closely monitored for signs of serious problems and given supportive treatment, such as fluids and oxygen [1-4, 7-9].

Chlorogenic acid (CGA) is a polyphenol that is an ester of caffeic acid and quinic acid (Fig. 1). It is primarily found in green (unroasted) coffee beans, cocoa leaves and seeds, yerba mate (dried, ground leaves of a native species of holly tree, Ilex paraguariensis), hawthorn, yam, artichoke, blueberry, chokeberry and mulberry, tomatoes, raw potatoes, but also in honey and some herbs [10-13]. According to the findings of some studies, regular consumption of green

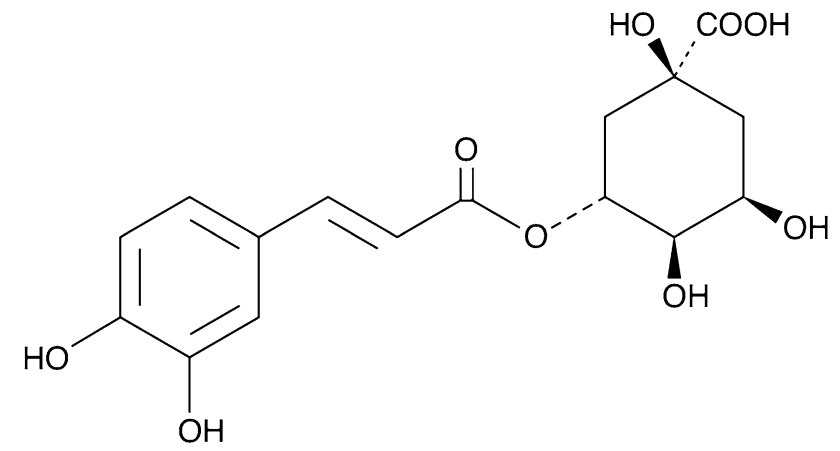

Fig. 1 Chemical structure of chlorogenic acid (5-caffeoylquinic acid, CGA), which is formed via the esterification of caffeic acid and quinic acid

coffee may have antibacterial, anti-inflammatory, and anticancer properties. [14, 15]. CGA can also help to reduce the absorption of carbohydrates from food and lower blood pressure [16, 17]. Furthermore, it has been proposed that CGA may improve brain function and have neuroprotective effects on its own [18]. Contrastingly, the results of many studies present that CGA has an anti-inflammatory effect. This compound is said to decrease the inflammatory response by indirectly inhibiting the expression of pro-inflammatory cytokines (interleukin (IL)-1 $\beta$, IL-6, tumor necrosis factor $\alpha(\mathrm{TNF}-\alpha)$ ) and chemokines (including chemokine (C-X-C motif) ligand 1, IL-8) [19]. CGA also reduces the concentration of prostaglandins, which are inflammation mediators, and nitric oxide, which reacts with free radicals to form compounds that can damage DNA and cause mutations by inhibiting cyclooxygenase-2 (COX-2) [10, 12, 13, 15, 19].

Even though the beneficial role of CGA is well-explored in many inflammatory diseases [10], the effects of CGA on established AP have not been examined. In this study, we tested the anti-inflammatory effect of CGA using the mouse model of L-arginine-induced AP which is well known as a mimic of clinical pancreatitis and is commonly used to evaluate the effects of phytochemicals [20-22].

\section{Materials and methods}

\section{Animals}

Male C57BL/6 mice, 8-12 weeks of age, were obtained from the Animal House at the University of Lodz, Lodz, Poland. All animals were housed in standard rodent cages in a climate-controlled room with an ambient temperature of $23 \pm 2{ }^{\circ} \mathrm{C}$ and 12:12 h light-dark cycle. Animals were fed standard laboratory chow, given water ad libitum, and randomly assigned to control or experimental groups. All animal protocols were approved by the Medical University of 
Lodz Animal Care Committee (\#70/LB83/2017). All efforts were made to minimize animal suffering and to reduce the number of animals used.

Animals were divided into three experimental groups $(n=8)$ :

1. Control

2. Mice with acute pancreatitis (AP)

3. Mice with acute pancreatitis treated with CGA $(\mathrm{AP}+\mathrm{CGA})$

\section{Induction of acute pancreatitis}

A sterile solution of L-arginine hydrochloride (8\%) was prepared in normal saline, and the $\mathrm{pH}$ was adjusted to 7.0. The arginine solution was administered intraperitoneally ( $i p$ ) to nonfasted mice at a dose of $4 \mathrm{~g} / \mathrm{kg} \mathrm{BW}$. Animals were then returned to the cages and allowed free access to food and water. After $1 \mathrm{~h}$, animals were administered a second dose of L-arginine hydrochloride solution $(4 \mathrm{~g} / \mathrm{kg} \mathrm{BW})$ in saline. Controls received each time a sham injection of saline alone. Mice were weighed daily and monitored for clinical symptoms of pancreatitis [23].

\section{Pharmacological treatment}

CGA was administered two times daily at the dose of $20 \mathrm{mg} /$ $\mathrm{kg}$ orally (po, $150 \mu \mathrm{L})$ with the first treatment $12 \mathrm{~h}$ after induction of $\mathrm{L}$-arginine acute pancreatitis mouse model. CGA was dissolved in 5\% dimethyl sulfoxide (DMSO) in saline, which was used as vehicle. Control and AP mice received equivalent volume of vehicle every $12 \mathrm{~h}$. Mice were sacrificed at $72 \mathrm{~h}$. Pancreatic tissues were collected for histology in $4 \%$ buffered formalin as well as snap frozen in liquid nitrogen for myeloperoxidase (MPO) and amylase activity analysis.

\section{Determination of tissue myeloperoxidase (MPO) activity}

To monitor the degree of inflammation, MPO activity assay was performed as described earlier [24]. Following isolation, isolated pancreas sections were weighed and homogenized in hexadecyltrimethylammonium bromide (HTAB) buffer (final concentration-50 mg tissue/1 mL HTAB buffer) using a Precellys Evolution advanced tissue homogenizer (Bertin Instruments, France). Following centrifugation $\left(13,200 \mathrm{~g}, 15 \mathrm{~min}, 4^{\circ} \mathrm{C}\right)$, supernatants were collected from each Eppendorf tube and transferred to another Eppendorf tube. Further, $7 \mu \mathrm{L}$ of supernatant was added on each well on a 96-well plate, containing $200 \mu \mathrm{L}$ of $50 \mathrm{mM}$ potassium phosphate buffer ( $\mathrm{pH} 6.0), 0.167 \mathrm{mg} / \mathrm{mL}$ of O-dianisidine hydrochloride, and $0.05 \mu \mathrm{L}$ of $1 \% \mathrm{H}_{2} \mathrm{O}_{2}$. Absorbance was measured in triplicate at optical density (OD) $450 \mathrm{~nm}$ after 30 and 60 s (iMARK Microplate Reader, Biorad, UK). MPO was measured in milliunits per gram of wet tissue, with 1 unit equaling the amount of enzyme capable of converting $1 \mathrm{~mol}$ of $\mathrm{H}_{2} \mathrm{O}_{2}$ to water in $1 \mathrm{~min}$ at room temperature. MPO activity was measured in units (U) per minute using a standard curve and purified peroxidase enzyme.

\section{Determination of amylase activity in the pancreas}

Amylase Assay Kit (Colorimetric) (Abcam, ab102523) was used to detect activity of $\alpha$-amylase through a two-step reaction, according to manufacturer's protocol.

\section{Histology}

Pancreas tissue samples were fixed for $24 \mathrm{~h}$ in $4 \%$ buffered formalin, $\mathrm{pH} 7.2$, and processed automatically in a tissue processor (Leica TP-1020). Paraffin-embedded tissue samples were sectioned, mounted on slides, and stained with hematoxylin and eosin (H\&E); concurrently, Masson's trichrome staining and immunohistochemical reaction (IHC) were performed (see details below). Samples were examined using Nikon's Eclipse E600 light microscope (Nikon Instruments Inc., Japan). Photographs were taken using a digital imaging system consisting of a digital camera for microscopy (Nikon DS-Fi1, Nikon Instruments Inc., Japan) and image analysis software (NIS-Elements BR-2.20, Laboratory Imaging, Czech Republic). Morphological analyses were done by a pathologist blinded to the experimental protocol.

\section{H\&E staining}

Pancreas sections were stained with H\&E staining in accordance with standard protocol [25].

\section{Masson's trichrome staining}

The Masson's trichrome staining was conducted using standard protocol [26].

\section{IHC}

The immunohistochemical reaction was performed based on the indirect immunoperoxidase method using a detection system (UltraVision Quanto Detection System HRP, ThermoScientific) and chromogen (DAB Quanto, ThermoScientific). Anti-Collagen 1 polyclonal antibody (ab21286, Abcam) at a dilution of 1:250 and anti-matrix metalloproteinase 1 (MMP-1) polyclonal antibody (ab137332, Abcam) at a dilution of 1:500 were used. Incubation with primary antibodies in the humid chamber lasted $60 \mathrm{~min}$ at room temperature. To block endogenous peroxidase, $3 \%$ hydrogen 
peroxide solution with methanol was used. Reaction sites were unmasked in a water bath at $\mathrm{pH} 6$ and $95{ }^{\circ} \mathrm{C}$ to expose the epitopes. $2.5 \%$ horse serum solution (Normal Diluted Horse Serum, Vector Laboratories, USA) was used to block non-specific reaction sites. A tris-buffered saline (TBS, Sigma-Aldrich) solution was used instead of the original primary antibody to obtain negative control of the immunohistochemical assay. A hematoxylin solution (Novocastra, Leica Biosystems, USA) was used for counterstain of nuclei.

\section{Drugs}

All drugs and reagents, unless otherwise stated, were purchased from Sigma-Aldrich (Poznan, Poland). CGA (purity $98 \%$ by high-performance liquid chromatography) was extracted from honeysuckle flowers and purchased from Nanjing Zelang Medical Technology Co. (Nanjing, Jiangsu, China). In all in vivo tests, drugs were dissolved in $5 \%$ DMSO in saline, which was used as vehicle in control groups. Vehicle affected none of the measured parameters when given alone.

\section{Statistical analysis}

Statistical analysis was performed using Prism 9.0.1 (GraphPad Software Inc., La Jolla, CA, USA). The data are expressed as means \pm SEM. The Shapiro-Wilk test was used to test the normality of data distribution. One-way ANOVA followed by Bonferroni post hoc test as well as student $t$ test were used for analysis. $P$ value $<0.05$ were considered as statistically significant.

\section{Results}

\section{Administration of CGA attenuated pancreatitis in L-arginine-induced AP in mice}

Development of AP is accompanied by sequestration of neutrophils in the pancreas. Therefore, MPO activity in those tissues, which is a standard measurement of neutrophil infiltration, has been used as a biochemical marker of pancreatitis.

Mice treated only with L-arginine had highly significantly increased MPO activity in the pancreas after $72 \mathrm{~h}$ compared with the control group $(40.40 \pm 2.10 \mathrm{U}$ vs. $7.39 \pm 0.34$, Fig. 2A.; $p=0.000000000000081)$. Administration of CGA (po, $20 \mathrm{mg} / \mathrm{kg} \mathrm{BW}$ ) highly significantly reduced MPO activity in the pancreas $(15.40 \pm 0.74 \mathrm{U}$ vs. $40.20 \pm 2.10 \mathrm{U}$, Fig. 2A; $p=0.000000000009161)$ in the murine model of AP.
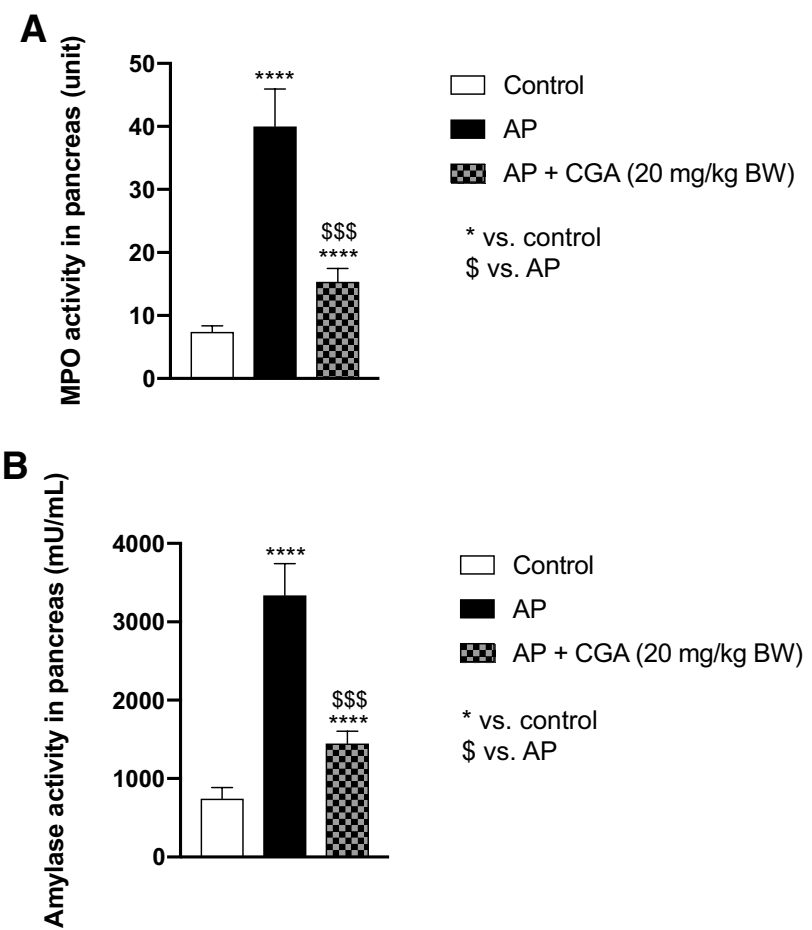

Fig. 2 Myeloperoxidase (MPO) activity (A) and amylase activity (B) in the pancreas in the control group, acute pancreatitis (AP) group and following administration of chlorogenic acid (CGA) after $72 \mathrm{~h}$ from the induction of AP. One-way analysis of variance (ANOVA) followed by Bonferroni correction test was used to evaluate the variables between groups. Bars represent mean \pm SEM of $n=8$ mice per group; $* * * p<0.0001$ as compared with control. ${ }^{\$ \$} p<0.001$ vs. AP

\section{Administration of CGA significantly reduced amylase activity in the pancreas in L-arginine-induced AP in mice}

Elevated plasma amylase is an important marker of pancreatic acinar cell injury $[6,27]$. Administration of L-arginine increased amylase activity in the pancreas compared to controls $(3340 \pm 144 \mathrm{mU} / \mathrm{mL}$ vs. $745 \pm 49 \mathrm{mU} / \mathrm{mL}$, Fig. $2 \mathrm{~B}$; $p=0.000000071764227)$. Administration of CGA significantly suppressed the increase of the amylase activity in mice with L-arginine induced AP compared with the AP group $(1444 \pm 56 \mathrm{mU} / \mathrm{mL}$ vs. $3340 \pm 144 \mathrm{mU} / \mathrm{mL}$, Fig. $2 \mathrm{~B}$; $p=0.000001245393492)$.

\section{Histological analysis revealed decreased severity of pancreatitis after CGA treatment in AP mice}

\section{H\&E staining (Fig. 3A-C)}

Histopathological evaluation of the H\&E-stained pancreas tissue sections from the L-arginine treated group revealed significant acinar cells dissociation, disruption of histoarchitecture, acinar cell vacuolization and edema, moderate acinar 
cells atrophy, and neutrophil infiltration (Fig. 3B). In contrast, no microscopical changes were observed in the control group (Fig. 3A). There was minimal inflammatory infiltrate in periacinar area and lack of atrophied acinar cells in the AP group treated with CGA (Fig. 3C).

\section{Masson's trichrome staining (Fig. 3D-F)}

Masson's trichrome staining is used for the detection of collagen fibers in the pancreas. The overall amount of collagen deposited by fibroblasts in the extracellular matrix (ECM) is a regulated balance between collagen synthesis and collagen catabolism, which is a carefully controlled process in the pancreas.

In the control group there was a minimal deposition of collagen fibers (Fig. 3D), while in the AP group there was a moderate collagen deposition in periacinar area (Fig. 3E). After treatment with CGA, collagen fibers deposition was observed only between individual acinar cells (Fig. 3F).

\section{IHC/anti-collagen 1 (anti-coll-1) (Fig. 3G-I)}

As collagen fibers deposition is important in the remodeling of the ECM of the pancreas and its severity is the hallmark of chronic pancreatitis, to confirm results from Masson's trichrome staining the IHC/anti-coll-1 reaction was performed. Collagen type I appeared as loose fibers surrounding acinar units and pancreatic islets. In the control group (Fig. 3G) there was a weak reaction between individual acinar cells, while in the AP group (Fig. $3 \mathrm{H}$ ) and in the AP group treated with CGA (Fig. 3I) there was a heterogenous moderate to strong immunohistochemical reaction.

\section{IHC/anti-MMP-1 (Fig. 3J-L)}

Matrix metalloproteinases (MMPs), which belong to the family of zinc-dependent endopeptidases, degrade most of the constituents of the ECM, basement membrane, as well as inflammatory mediators. Most of the MMPs are not expressed in the normal tissue, but their expression and activity increase dramatically during wound healing as a result of a change in ECM composition, inflammation, and repair [28].

In the control group MMP-1 protein was not detectable (Fig. 3J), while AP group showed strong expression of MMP-1 (Fig. $3 \mathrm{~K})$. In the AP group treated with CGA there was a multifocal weak to moderate immunoreactivity for MMP-1 (Fig. 3L).

\section{Discussion}

Polyphenols are an important ingredient in the diet, and approximately $50 \%$ of the daily intake of polyphenols are phenolic compounds [29]. As CGA is one of the most abundant phenolic compounds in the human diet, its antiinflammatory, antioxidant and various biological activities have been widely reported [10-12, 14, 30-32].

Acute pancreatitis is an inflammatory disease with a varied clinical course. Management is usually conservative, with interventional therapy reserved for those with complications [1,5]. In our study, we shed light upon the potential role of anti-inflammatory properties of CGA in the treatment of AP using the L-arginine animal model. The benefits of using this model are obvious: it is inexpensive, technically simple to execute, and only requires ip injections. The induction method is relatively noninvasive and does not require anesthesia or surgery. Moreover, it accurately reproduces the majority of laboratory and morphological features of human AP. One distinction between human and L-arginine-induced AP is that human disease is typically patchy in distribution, whereas L-arginineinduced AP is relatively homogeneous (more so the case in rats). Unfortunately, the dose of $\mathrm{L}$-arginine that causes $\mathrm{AP}$ is very close to the toxic dose, and the severity of the disease is difficult to control (particularly in mice) and administration of excessive doses of L-arginine can cause systemic toxicity and death of animals which might be a limitation of the study $[33,34]$.

The results of our experiments suggested that CGA may display a highly significant anti-inflammatory activity in a well-established mouse model of L-arginine-induced AP as evidenced by reduction of MPO activity and-noteworthy-histopathological changes (H\&E staining, Masson's trichrome staining, IHC/anti-coll-1, IHC/anti-MMP-1). Microscopically, AP is presented as an inflammatory tissue reaction to functional and/or structural acinar cell damage and rarely duct cell necrosis. Here, morphological assessment showed that the treatment with CGA after the induction of AP reduced inflammatory infiltrates in the periacinar area as well as there was a minimal atrophy of acinar cells. Moreover, lowered amylase activity in the pancreas of the AP group treated with CGA emphasized the positive effect of this compound on murine pancreas.

Our study, along with previously published reports, shows that CGA may become a new therapeutic or an attractive supplement in the treatment of AP. Moreover, our data show that CGA may have therapeutic activity and may be used in patients regardless of the current stage of the disease. Our observations elegantly complete the data obtained by Ohkawara et al. [35] who evaluated the protective effect of CGA on the inflammatory damage of 
CONTROL
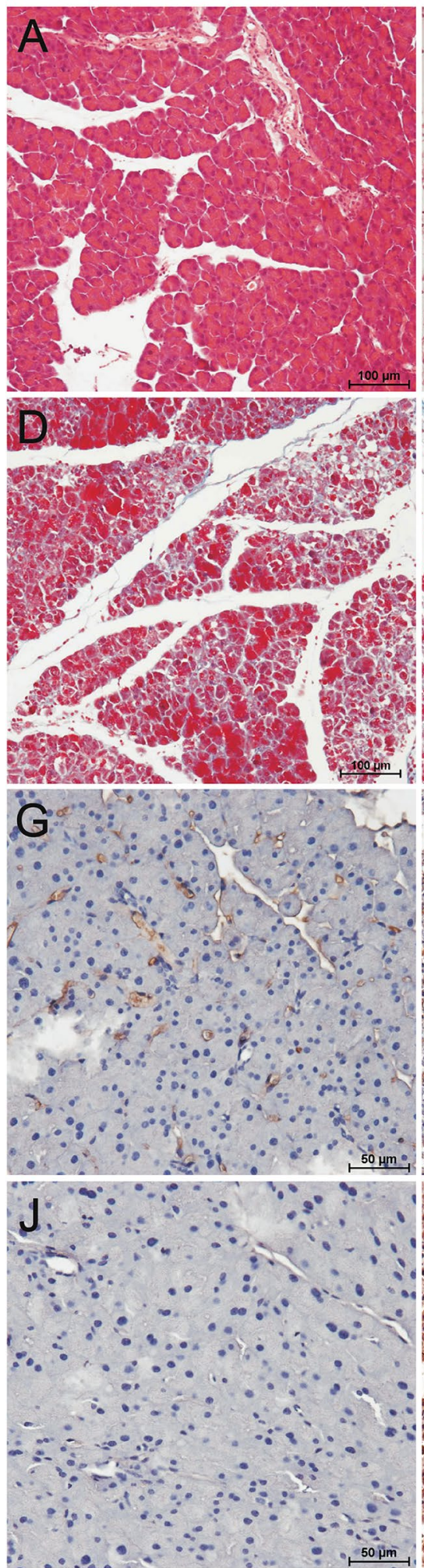

AP
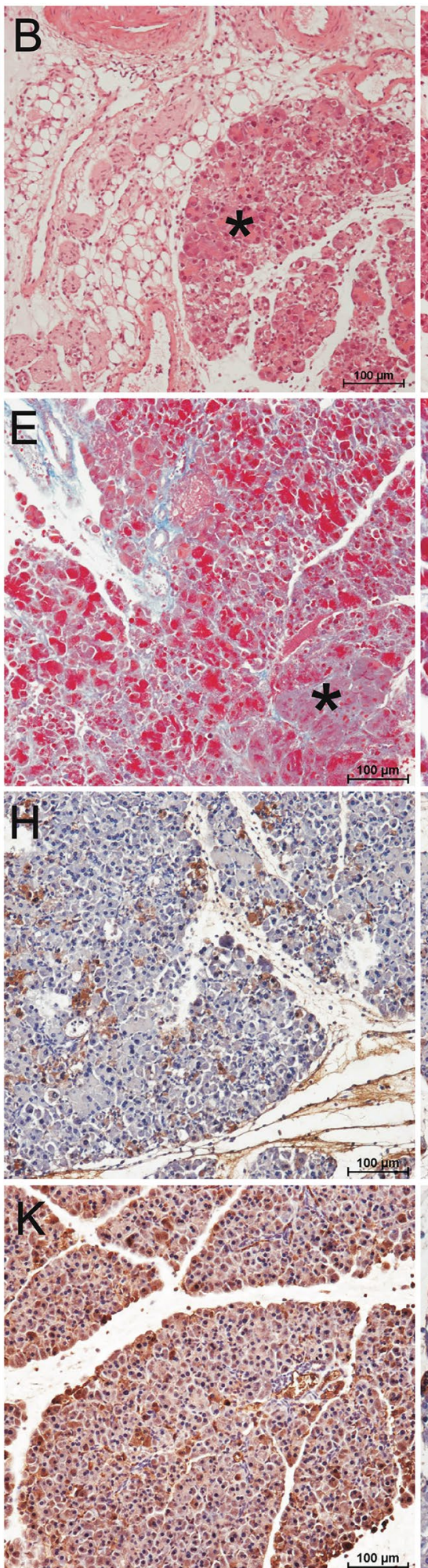

$A P+C G A$
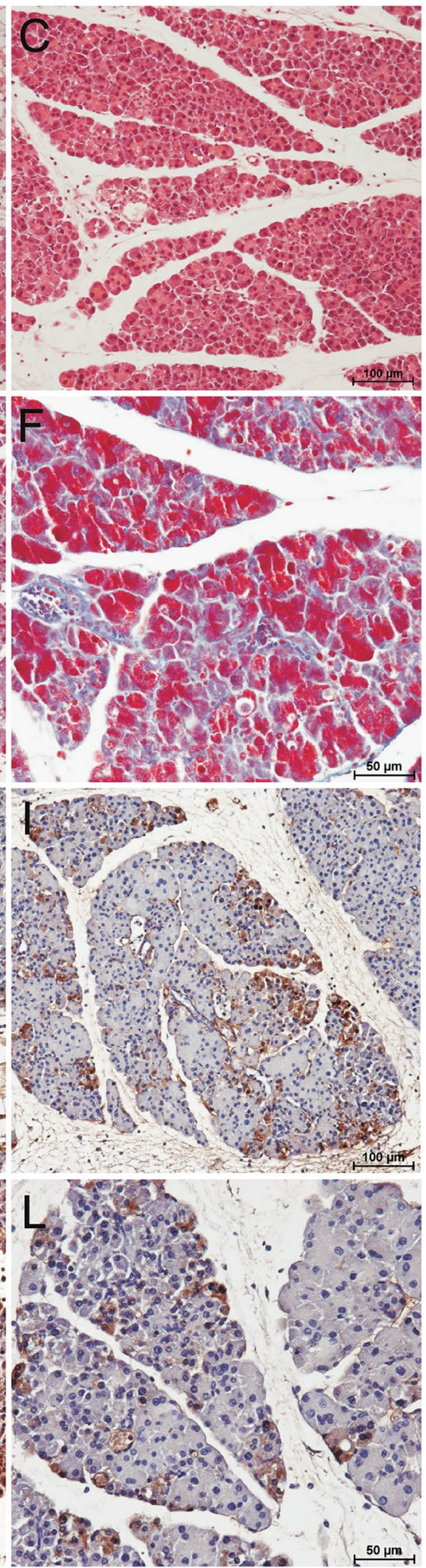

pancreas in mice with L-arginine-induced AP. In their study mice were $i p$ injected with CGA ( 20 and $40 \mathrm{mg} / \mathrm{kg}$ ) $1 \mathrm{~h}$ before administration of L-arginine. This pretreatment significantly decreased the histological severity of pancreatitis. Moreover, administration of CGA decreased the levels of pancreatic enzyme activity. Interestingly, CGA 
4Fig. 3 Representative microphotographs of the pancreas. H\&E staining: control group (A) - normal architecture of the pancreas; AP group (B) - inflammatory infiltrate in adjacent fatty tissue and distortion of acini (star); AP + CGA group (C) - minimal inflammatory infiltrate in periacinar area and lack of atrophied acinar cells. Masson's trichrome staining: control group (D) - minimal deposition of collagen fibers in periacinar area; AP group (E)-moderate collagen deposition in periacinar area and distinct atrophied acinar cells (star); AP + CGA group (F)—increased collagen fibers deposition between individual acinar cells. IHC/anti-Coll-1: control group (G) - weak reaction between individual acinar cells, AP group $(\mathrm{H})$ and $\mathrm{AP}+\mathrm{CGA}$ group (I)—heterogenous distribution of moderate to strong immunohistochemical reaction. IHC/anti-MMP-1: control group $(\mathrm{J})$ —negative reaction; AP group $(\mathrm{K})$ — strong positive reaction; AP + CGA (L) - multifocal weak to moderate reaction. Samples were examined using Nikon's Eclipse E600 light microscope (Nikon Instruments Inc., Japan). Photographs were taken using a digital imaging system consisting of a digital camera for microscopy (Nikon DS-Fi1, Nikon Instruments Inc., Japan) and image analysis software (NIS-Elements BR-2.20, Laboratory Imaging, Czech Republic)

reduced the serum and pancreatic levels of macrophage migration inhibitory factor (MIF) - a pro-inflammatory cytokine, which is implicated in cancer (i.e., it is found in many human cancer and cancer-prone inflammatory diseases, including chronic pancreatitis and pancreatic cancer) and may be characterized as critical mediator of severe AP [35, 38, 39]. Even though our study might be seen as similar to the research of Ohkawara et al. [35], it needs to be underlined here that we tried to evidence the anti-inflammatory, rather than preventive or protective, effect of CGA.

A limitation of the study is the lack of additional experimental group: mice with CGA alone. However, the chosen dosage of CGA is $20 \mathrm{mg} / \mathrm{kg}$ BW twice daily which is about $1200 \mathrm{mg} / 60 \mathrm{~kg} \mathrm{BW}$ for the human being. A clinical study employing this dose has already been conducted (https:// clinicaltrials.gov/ct2/show/study/NCT02621060, https:// clinicaltrials.gov/ct2/show/NCT02136342) and there was no evidence for this dose being toxic. Second, we have designed our study based on the published literature [35] in which similar doses were used. Furthermore, previous studies have shown that CGA has an anti-inflammatory effect under inflammatory conditions such as liver injury in mice [36]. In animal models of IBD, administration of CGA significantly reduced the severity of colitis induced by dextran sulfate sodium in C57BL/6 mice [37].

We are also aware of the limitations of the study resulting from the use of an animal model due to anatomical and physiological differences. On the one hand, human studies are inherently limited to small samples at irregular and often unpredictable intervals, and therefore animal models have largely subdued the research field, with the mouse model being the most used [40]. On the other hand, in human pancreas the bile and pancreatic ducts are separate ducts that normally form a very short common channel in the duodenal wall, whereas those of the rat form a long common channel with the bile duct also serving as a conduit of pancreatic juice. Further, the mouse pancreas is not a well-defined solid organ like in humans, but rather is a diffusely distributed soft tissue while the human pancreas is a single solid organ abutting the duodenal wall. Notwithstanding, there are also some common features between mouse and human pancreas. First, the pancreatic duct drains into the duodenum. Second, cellular components such as acinar, ductal, stellate, and endocrine cells are similar. Third, the mouse pancreas also performs exocrine and endocrine functions [41]. Therefore, another limitation of the study are the morphological differences between human and mouse pancreatic tissue which appear to be numerous, implying that human tissue should be included in basic and applied research [40].

Finally, though most research on CGA shows that it is a fairly safe dietary supplement, one study showed that the use of CGA in combination with a high-fat diet not only does not contribute to weight loss, but also does not protect experimental animals against the adverse metabolic consequences of such a diet [30]. Moreover, the absorption and bioavailability of CGA are still debated due to the large interindividual variations in its utilization, metabolism, and excretion evidenced in both basic and clinical studies [17, 42, 43]. Finally, further research into the therapeutic effects of CGA requires an assessment of its longterm effectiveness and possible side effects of the therapy. Therefore, large and well-designed randomized trials are needed to fully characterize and then exploit the potential of CGA. Nevertheless, the results we obtained along with previous papers suggest that CGA may become an effective and safe drug (proposed dosage: $1200 \mathrm{mg} / 60 \mathrm{~kg} \mathrm{BW}$ for the human being) or supplement successfully used in the prevention and treatment of AP.

Author contributions AT and JF provided the overall concept and designed the research study; JF and AT conducted experiments; KB performed the histological assessment; MT performed statistical analysis; AT analyzed the data and wrote the manuscript. AT, JF, MT, and $\mathrm{KB}$ revised the manuscript. All authors regularly discussed the experiments and data, suggested adjustments of the experimental protocols, read, and approved the final version of the manuscript.

Funding Supported by a grant from the Medical University of Lodz (\#503/1-156-04/503-11-001-19-00 to JF).

\section{Declarations}

Conflict of interest The authors declare no conflict of interest regarding the study. 
Open Access This article is licensed under a Creative Commons Attribution 4.0 International License, which permits use, sharing, adaptation, distribution and reproduction in any medium or format, as long as you give appropriate credit to the original author(s) and the source, provide a link to the Creative Commons licence, and indicate if changes were made. The images or other third party material in this article are included in the article's Creative Commons licence, unless indicated otherwise in a credit line to the material. If material is not included in the article's Creative Commons licence and your intended use is not permitted by statutory regulation or exceeds the permitted use, you will need to obtain permission directly from the copyright holder. To view a copy of this licence, visit http://creativecommons.org/licenses/by/4.0/.

\section{References}

1. Lankisch PG, Apte M, Banks PA. Acute pancreatitis. Lancet (London, England). 2015;386(9988):85-96.

2. Greenberg JA, et al. Clinical practice guideline: management of acute pancreatitis. Can J Surg. 2016;59(2):128-40.

3. James TW, Crockett SD. Management of acute pancreatitis in the first 72 hours. Curr Opin Gastroenterol. 2018;34(5):330-5.

4. Lee PJ, Papachristou GI. New insights into acute pancreatitis. Nat Rev Gastroenterol Hepatol. 2019;16(8):479-96.

5. Siva S, Pereira SP. Acute pancreatitis. Medicine (Baltimore). 2007;35(3):171-7.

6. Tenner S, Baillie J, DeWitt J, Vege SS. American college of gastroenterology guideline: management of acute pancreatitis. Am J Gastroenterol. 2013;108(9):1400-15 (1416).

7. Waller A, Long B, Koyfman A, Gottlieb M. Acute pancreatitis: updates for emergency clinicians. J Emerg Med. 2018;55(6):769-79.

8. Garg PK, Singh VP. Organ failure due to systemic injury in acute pancreatitis. Gastroenterology. 2019;156(7):2008-23.

9. Mandalia A, Wamsteker E-J, DiMagno MJ. Recent advances in understanding and managing acute pancreatitis. F1000Res. 2018;7:F1000 Faculty Rev-959 https://doi.org/10.12688/f1000 research.14244.2. PMID: 30026919;PMCID: PMC6039949.

10. Tajik N, Tajik M, Mack I, Enck P. The potential effects of chlorogenic acid, the main phenolic components in coffee, on health: a comprehensive review of the literature. Eur J Nutr. 2017;56(7):2215-44.

11. Wu Y, et al. Dietary chlorogenic acid regulates gut microbiota, serum-free amino acids and colonic serotonin levels in growing pigs. Int J Food Sci Nutr. 2018;69(5):566-73.

12. Sanchez MB, Miranda-Perez E, Verjan JCG, de los Angeles Fortis M, Barrera J-R, Alarcon-Aguilar FJ. Potential of the chlorogenic acid as multitarget agent: Insulin-secretagogue and PPAR $\alpha / \gamma$ dual agonist. Biomed Pharmacother. 2017;94:169-75.

13. Tarasiuk A, Fichna J. Effectiveness and therapeutic value of phytochemicals in acute pancreatitis: a review. Pancreatology. 2019;19(4):481-7.

14. Naveed M, et al. Chlorogenic acid (CGA): a pharmacological review and call for further research. Biomed Pharmacother. 2018;97:67-74.

15. Sato $Y$, et al. In vitro and in vivo antioxidant properties of chlorogenic acid and caffeic acid. Int J Pharm. 2011;403(1-2):136-8.

16. Onakpoya IJ, Spencer EA, Thompson MJ, Heneghan CJ. The effect of chlorogenic acid on blood pressure: a systematic review and meta-analysis of randomized clinical trials. J Hum Hypertens. 2015;29(2):77-81.

17. Watanabe T, Kobayashi S, Yamaguchi T, Hibi M, Fukuhara I, Osaki N. Coffee abundant in chlorogenic acids reduces abdominal fat in overweight adults: a randomized, double-blind, controlled trial. Nutrients. 2019;11(7):1617.
18. Heitman E, Ingram DK. Cognitive and neuroprotective effects of chlorogenic acid. Nutr Neurosci. 2017;20(1):32-9.

19. Hwang SJ, Kim Y-W, Park Y, Lee H-J, Kim K-W. Anti-inflammatory effects of chlorogenic acid in lipopolysaccharide-stimulated RAW 264.7 cells. Inflamm Res Off J Eur Histamine Res Soc. 2014;63(1):81-90.

20. Dawra R, Sharif R, Phillips P, Dudeja V, Dhaulakhandi D, Saluja AK. Development of a new mouse model of acute pancreatitis induced by administration of L-arginine. Am J Gastrointest Liver Physiol. 2006;292(4):G1009-18. https://doi.org/10.1152/ajpgi. 00167.2006

21. Foster JR. A review of animal models of nonneoplastic pancreatic diseases. Toxicol Pathol. 2014;42(1):243-59.

22. Su KH, Cuthbertson C, Christophi C. Review of experimental animal models of acute pancreatitis. HPB (Oxford). 2006;8(4):264-86.

23. Dawra R, Sharif R, Phillips P, Dudeja V, Dhaulakhandi D, Saluja AK (2007) Development of a new mouse model of acute pancreatitis induced by administration of $\mathrm{L}-\operatorname{arginine}$. $1009-1018$.

24. Fichna J, et al. Salvinorin A has antiinflammatory and antinociceptive effects in experimental models of colitis in mice mediated by KOR and CB1 receptors*. Inflamm Bowel Dis. 2012;18(6):1137-45.

25. Cardiff RD, Miller CH, Munn RJ. Manual hematoxylin and eosin staining of mouse tissue sections. Cold Spring Harb Protoc. 2014;2014(6):655-8.

26. Bancroft JD, Gamble M. Theory and practice of histological techniques. London: Churchill Livingstone; 2008.

27. Matull WR, Pereira SP, O'Donohue JW. Biochemical markers of acute pancreatitis. J Clin Pathol. 2006;59(4):340-4.

28. Marrache F, et al. Overexpression of interleukin-1beta in the murine pancreas results in chronic pancreatitis. Gastroenterology. 2008;135(4):1277-87.

29. Del Bo' C, et al. Systematic review on polyphenol intake and health outcomes: is there sufficient evidence to define a health-promoting polyphenol-rich dietary pattern? Nutrients. 2019;11(6):1355.

30. Mubarak A, Hodgson JM, Considine MJ, Croft KD, Matthews VB. Supplementation of a high-fat diet with chlorogenic acid is associated with insulin resistance and hepatic lipid accumulation in mice. J Agric Food Chem. 2013;61(18):4371-8.

31. Jung H-J, Im S-S, Song D-K, Bae J-H. Effects of chlorogenic acid on intracellular calcium regulation in lysophosphatidylcholinetreated endothelial cells. BMB Rep. 2017;50(6):323-8.

32. Bagdas D, Gul Z, Meade JA, Cam B, Cinkilic N, Gurun MS. Pharmacologic overview of chlorogenic acid and its metabolites in chronic pain and inflammation. Curr Neuropharmacol. 2020;18(3):216-28.

33. Hegyi $\mathrm{P}$, et al. L-arginine-induced experimental pancreatitis. World J Gastroenterol. 2004;10(14):2003-9.

34. Kui B, et al. Recent advances in the investigation of pancreatic inflammation induced by large doses of basic amino acids in rodents. Lab Invest. 2014;94(2):138-49.

35. Ohkawara T, Takeda H, Nishihira J. Protective effect of chlorogenic acid on the inflammatory damage of pancreas and lung in mice with 1-arginine-induced pancreatitis. Life Sci. 2017;190:91-6.

36. Zhou Y, et al. Chlorogenic acid ameliorates endotoxin-induced liver injury by promoting mitochondrial oxidative phosphorylation. Biochem Biophys Res Commun. 2016;469(4):1083-9.

37. Shin HS, et al. Anti-inflammatory effect of chlorogenic acid on the IL-8 production in Caco-2 cells and the dextran sulphate sodium-induced colitis symptoms in C57BL/6 mice. Food Chem. 2015;168:167-75. 
38. Sakai Y, Masamune A, Satoh A, Nishihira J, Yamagiwa T, Shimosegawa T. Macrophage migration inhibitory factor is a critical mediator of severe acute pancreatitis. Gastroenterology. 2003;124(3):725-36.

39. Funamizu N, et al. Macrophage migration inhibitory factor induces epithelial to mesenchymal transition, enhances tumor aggressiveness and predicts clinical outcome in resected pancreatic ductal adenocarcinoma. Int J cancer. 2013;132(4):785-94.

40. Dolenšek J, Rupnik MS, Stožer A. Structural similarities and differences between the human and the mouse pancreas. Islets. 2015;7(1):e1024405.

41. Hyun JJ, Lee HS. Experimental models of pancreatitis. Clin Endosc. 2014;47(3):212-6.
42. van Dijk AE, Olthof MR, Meeuse JC, Seebus E, Heine RJ, van Dam RM. Acute effects of decaffeinated coffee and the major coffee components chlorogenic acid and trigonelline on glucose tolerance. Diabetes Care. 2009;32(6):1023-5.

43. Clifford MN, Kerimi A, Williamson G. Bioavailability and metabolism of chlorogenic acids (acyl-quinic acids) in humans. Compr Rev food Sci food Saf. 2020;19(4):1299-352.

Publisher's Note Springer Nature remains neutral with regard to jurisdictional claims in published maps and institutional affiliations.

\section{Authors and Affiliations}

\section{Aleksandra Tarasiuk ${ }^{1} \cdot$ Kamila Bulak $^{2} \cdot$ Marcin Talar $^{1} \cdot$ Jakub Fichna ${ }^{1}$ (]}

Aleksandra Tarasiuk

tarasiuk.aleksandra@gmail.com

Kamila Bulak

kamila.bulak@up.lublin.pl

Marcin Talar

marcin.talar@umed.lodz.pl
Department of Biochemistry, Faculty of Medicine, Medical University of Lodz, Lodz, Poland

2 Sub-Department of Pathomorphology and Forensic Veterinary Medicine, Department and Clinic of Animal Internal Diseases, Faculty of Veterinary Medicine, University of Life Sciences in Lublin, Lublin, Poland 